\title{
Public Health Workforce in Latin America and the Caribbean: assessment of education and labor in 17 countries
}

\author{
Laura Magaña-Valladares, DAEduc, (') Gustavo Nigenda-López, DCSoc y Admon, (I) \\ Nidia Sosa-Delgado, M en SP, (I) José Arturo Ruiz-Larios, Soc. ${ }^{(I)}$
}

$\mathrm{H}$ ealth systems in Latin America and the Caribbean have experienced a series of reforms since the 1990 s as a result of the identification of problems with populations accessing services, scarce resources available to finance health, inequality in access to available resources, and issues concerning efficiency and quality of services. The reforms led to a redefining of the model of care from one that had focused resources on the production of personal services in the clinical environment to those that facilitate health promotion and risk prevention.

These reforms have opened the door to a greater utilization of new public health models that address the challenges created by the epidemiological transition, the aging of the population, and the increase in service production costs. International organizations such as the World Health Organization (WHO) and development banks, for example, are promoting a model known as Essential Public Health Functions (EPHFs), with the goal of health systems implementing its basic principles.

There is no doubt that since the proposal of these reforms, there are monumental challenges with respect to implementing new public health models based on EPHF. Their implementation requires, among other factors, a great deal of political commitment by key actors (including health ministries, social security institutions and professional associations), technically capable institutional leadership, and a well-informed civil society.
Health personnel is fundamental to this process. Human resources in the sector play an active change role, as their functions as educators, trainers, and counselors are determining factors for the successful development of such models.

In various countries, the transformations generated in the public health field have directly determined the need for highly qualified human resources to promote the implementation of models based on public health principles. It has therefore been necessary not only to revise the curricula currently in place at academic institutions but also to seek educational formats that enable the training of public health human capital to be broadened to better respond to the growing demand for these resources.

In addition, once human resources are trained, it is important to guarantee their integration into the workforce, since it is in this environment that the knowledge and skills acquired in training become actions. Public health personnel, therefore, must not only carry out technical tasks but also possess the ability to lead processes. However, one of the greatest obstacles to incorporating health workers into the workforce is that graduates tend to not be attracted to the labor markets, which tend to generate high attrition rates and, consequently, result in wastage in human and financial capital.

Thus, the participation of public health workers has become a privileged field of study and analysis since, ac-

This study was carried by requirements of the Public Health Foundation of India.The information presented in the version was selected and summariized from the original final report.

Participant countries: Belize, Colombia, Costa Rica, Cuba, Dominica, Ecuador, El Salvador, Granada, Guatemala, Haiti, Honduras, Jamaica, Mexico, Nicaragua, Panama, Dominican Republic,Venezuela. 
cording to initial findings, supply has increased in recent years but demand has not. It is, therefore, valuable to evaluate the form and content of educational programs as well as options for integration into the workforce. In particular, it is important to monitor graduate programs in terms of their field of application and the way in which they respond to the needs and expectations of those programs. It is also important to acknowledge the limited role educational institutions have played in the processes of transforming health systems in almost all of the countries in the Americas.

Training in public health should be in keeping with the challenges that the health system currently faces, which include a demographic change that has completely changed the age structure of the population, including in Latin America, and consequently, the development of an epidemiological transition that is leading to an increase in chronic-degenerative diseases, accidents, addictions, and violence. Faced with this challenge, public health training programs must adequately direct their content toward the current health needs of the population.

In Latin America, public health must also confront the challenge of reforming the organization, policies, leadership, funding, and management of health systems in such a way that they more adequately respond to the population's health needs at a lesser cost. Training programs should reflect these changes so that graduates may actively participate in necessary and essential changes to health systems.

Public health training programs should utilize the Essential Public Health Functions ${ }^{1}$ as a conceptual point of reference to organize public health interventions according to functional groups that are limited and identifiable from an operational perspective, and to define their purpose, objectives, activities, resources, and organization according to that which is essential to the improvement of population health. In addition, the type of human resources that must be trained by educational institutions is influenced by the health system reforms in different countries across the region, that not only entail new models of care, as previously mentioned, but also identify new priorities and search for alternative funding; an unavoidable condition for improving the quality of education in the classroom and school, as well as in an area, region, and country. ${ }^{2}$

This document addresses the field of public health education and the conditions in which public health personnel is integrated into the labor market. One of the purposes of the report is to investigate the characteristics of public health educational programs and their relation to the needs of national health systems.

\section{Methodology}

The first section of this document is based on both secondary sources, including documents and online research, as well as primary sources, including direct requests for information from institutions via telephone. The countries consulted were: Costa Rica, El Salvador, Guatemala, Mexico, Venezuela, Ecuador, Jamaica, Honduras, the Dominican Republic, Colombia, Cuba, Panama, and Nicaragua. There is no information on the rest of the countries in the region (Granada, Dominica, and Belize), either because there are no human resources training programs in the area or because this information is not available by the means of research used. One of the main limitations of this work is the lack of information on internet web pages about educational institutions in Latin America, which made it difficult to obtain more reliable data on the different graduate programs analyzed.

The aspects explored for each of the programs and institutions across the countries were: clear definition of mission and vision; program competencies or objectives; the institution's predominant educational model; educational formats offered in the programs, especially in the Master of Public Health or equivalent; bodies offering national or international accreditation or recognition of the various institutions; general admissions requirements; whether the program has a specific concentration area; the existence of a formal student tutoring program and scholarship program; the institution's fieldwork experience; the existence and results of an alumni tracking program, continuing education program, and career services.

For the second section of this report, a wide document search was performed to collect information on the number and categories of personnel that are public health specialist in addition to those who work in public health, as defined by their work functions. In the case of physicians, nurses, and dentists, data was collected for those who have patient contact and perform primary care.

With respect to the employment conditions of graduates from public health training institutions, the Pan American Health Organization (PAHO) Observatories of Human Resources and other specialized literature on this theme were reviewed. Specific information for public health personnel was not found, but rather for the health workforce in general. Nevertheless, through telephone interviews with key informants, we sought qualitative information related to the integration of trained public health personnel into the labor market as well as their institutional, sectoral (public or private), and geographic (rural or urban) position, and work 
characteristics (level of hierarchy, average income, employment benefits). Factors related to the working environment were also considered.

\section{Existing programmatic frameworks and curricula for public health education}

The transformations generated in the field of public health as a consequence of health reforms and health profile changes in LAC have directly determined the need for highly trained human resources to face the population's new health demands. It has therefore been necessary not only to revise the curricula currently in place at academic institutions but also to seek educational formats that enable the training of public health human capital to be broadened so as to better respond to the growing demand for these resources.

Graduate programs in public health have multiplied in recent years and have continued to adapt to the trends and tendencies that have appeared within the discipline and to the type of health services offered nationally; they thus represent a privileged area to understand the changes that have been occurring in the field of public health theory and practice. Consequently, it is valuable to have mechanisms that review the form and content of training programs, with the aim of monitoring their field of application and becoming familiar with the way in which they respond to needs and expectations of those programs. In this sense it is also important to recognize the limited role educational institutions specializing in the subject have played in the processes of transforming health systems in almost all of the countries in the Americas.

There are currently 12 countries from the 16 analyzed, in Latin America that offer formal and well-established education and training programs in public health. It is important to emphasize that in this study the majority of educational institutions analyzed are affiliated with the Latin American Association of Schools of Public Health (ALAESP), a civil organization that brings together mainly public institutions and programs dedicated to teaching in the field of public health. The Association was created in 1974 in Lima, Peru and its leadership is currently made up of representatives from Chile, Cuba, and Mexico. Its objective is to develop education and research to strengthen the health system and improve the living conditions of the population, to promote necessary changes in health policy and services, and to promote exchange and technical cooperation between the different institutions that comprise ALAESP. ${ }^{4}$

\section{Public Health Education}

The origin of public health education in the region, defined by this study, dates to the early 20th century with the founding of the Escuela de Salubridad e Higiene [School of Health and Hygiene] in Mexico, in 1922. This institution became the Mexican School of Public Health and is now part of the National Institute of Public Health, where the Master of Public Health was first offered in 1949. In 1927, Cuba's National School of Public Health was founded. It is one of the most representative schools on the American continent and serves as a regional reference center; it has an internationally recognized staff and a high level of excellence in teaching, research, and population services. In 1964, the Public Health Department of the University of Antioquia in Colombia was founded--a precursor to the exponential growth of academic programs that arose in the 1980s which included the creation of the graduate program in public health at the University of Veracruz, Mexico. In fact, the main institutions that train professionals in the field were founded in the last quarter of the 20th century, and there are now 42 such institutions in the study area that are creating a wealth of human capital for public health in the region.

Academic training in public health throughout Latin America and the Caribbean has strong social roots; its theoretical contrast lies in ideology and culture, politics, economics, and the predominant contemporary public health thinking. ${ }^{5}$ For example, some countries -such as Ecuador, Cuba and Mexico, to cite a few- use an economic and social approach aimed at analyzing and considering the demographic and epidemiological changes occurring at the regional level. Therefore, factors such as the role of professionals in devising health policy, in searching for new means of strengthening national and international capacities, and in the inclusion of issues related to providing primary care to the population merge with the basic and traditional aspects of academic training in public health.

\section{Undergraduate and Specialization Programs}

Programs geared towards human resources training in public health and related areas in the region range from the bachelor's degree or undergraduate level to the master's (MPH) and doctorate degrees, although the vast majority of programs in the region are concentrated in the MPH. There are few bachelor's level programs, among which the following two stand out: 
the Autonomous University of Aguascalientes (Mexico), with an undergraduate public health program, and the University of Antioquia (Colombia), with five undergraduate programs in the field.

At the specialized level, 15 programs were identified. These include a specialization in Public Health Nursing in Mexico, a specialization in Public Health Administration in Venezuela, three specializations in Ecuador (Health Economics, Primary Care and Community Health Sciences), and eight in Colombia (Public Health, Epidemiology, Health Administration, Health Auditing, Health Systems Administration, Occupational Health, and Comprehensive Control of Health Services Management and Auditing). There is also a Medical Residence in Public Health and Preventative Medicine in Mexico.

\section{Master's and Doctorate Degree Programs}

A total of 58 programs were reported as offering a master's degree: 26 in Public Health with various concentration areas, 23 in areas related to public health all of them with a professional approach, and nine with academic orientation in Public Health Sciences. Nine doctorate programs were identified: five in Public Health (Colombia and Mexico), one in areas related to public health (Colombia), and three in Health Sciences (Mexico).

Public health programs have been the object of continuous changes resulting from pressure from the labor market. For example, the Master of Public Health program at the National University of Colombia was suspended for 12 years in order to redesign the curriculum and respond to the population's health needs. In addition, the National University of Colombia's Master of Public Health is a research graduate program with multi-professional admissions (physicians, nurses, social scientists, engineers, economists, etc.) with a foursemester curriculum that combines in-person and virtual activities with independent student work.

New programs are continually being developed throughout the countries, as in the case of the National University of Honduras that has been operating for approximately six years. Another case is the newly created Master of Public Health program at the University of San Carlos of Guatemala, which is in a stage of curriculum development, with the first graduating class entering in January of 2009.

The institutions studied have made a great effort to incorporate current public health needs into their programs; in particular, the experience of the National Autonomous University of Nicaragua should be recognized. This program has demonstrated its effort in the region by including traditionally marginalized groups in its Intercultural Public Health program. This experience permitted an understanding of the urban and the rural, the regional and the local, the multicultural and the intercultural, and the institutional and the communal. Although in practice it represented a process of integrating knowledge as students advanced in the completion of the master's degree, the content of the program's curriculum was innovative and it used a process of mutual learning and exchange between faculty and ethnic communities.

Concentration Areas for Masters of Public Health and Health Sciences

Another relevant element in the Master of Public Health programs analyzed is the goal of training public health professionals with an emphasis on problems affecting developing countries. In addition, public health is a field of knowledge with trans-disciplinary transformation; ${ }^{6}$ it is, thus, pertinent to mention that in some countries, institutions with Master of Public Health programs have concentration areas that are clearly defined in terms of various other disciplines. Thus, the human capital trained is more diverse and achieves levels of specialization that enable work to be performed in more specific operational areas (Table I).

Among the institutions that offer the Master of Public Health whose curricular plans were accessible, some uniformity could be observed in areas of general knowledge such as epidemiology, biostatistics, and health systems, while great diversity was observed in the concentration areas. The Mexican, Cuban, Nicaraguan, and Ecuadorian programs incorporate the practicum experience into the curricula (Table II).

Some master's programs have already included in their curricula an ecological approach to health, with an emphasis in health promotion and primary health care, as in the case of Cuba, who in addition to the MPH offers the following programs:

- Health Promotion and Education

- Primary Health Care

- School Health

- Healthy Housing

- Occupational Health

The cases of Costa Rica, Mexico, and Cuba should be emphasized, as they have been increasing the types of programs offered in order to address specific areas of concern for public health, such as:

- Health Psychology

- Health and Aging 


\section{Table I}

INSTITUTIONS OFFERING PUBLIC HEALTH PROGRAMS, Representative of Concentration Areas

\begin{tabular}{ll}
$\begin{array}{l}\text { MPH Concentration Area } \\
\text { The Environment and }\end{array}$ & \multicolumn{1}{c}{ Institutions } \\
\hline Human Development & \\
\hline Health Policy & University of Costa Rica \\
\hline Adolescence and Youth & University of Costa Rica \\
\hline Health Services & University of Costa Rica \\
Management & $\begin{array}{l}\text { Rafael Landivar University of } \\
\text { Guatemala } \\
\text { Universidad San Francisco de Quito }\end{array}$ \\
\hline Epidemiology & $\begin{array}{l}\text { Rafael Landivar University of } \\
\text { Guatemala }\end{array}$ \\
& $\begin{array}{l}\text { National Institute of Public Health } \\
\text { of Mexico } \\
\text { National Autonomous } \\
\text { University of Nicaragua }\end{array}$ \\
\hline Social and Behavioral & National Institute of Public Health of Mexico \\
\hline Sciences & National Institute of Public Health of Mexico \\
\hline Biostatistics & National Institute of Public Health of Mexico \\
\hline Health Administration & National Institute of Public Health of Mexico \\
\hline Environmental Health & National Institute of Public Health of Mexico \\
\hline Nutrition & National Institute of Public Health of Mexico \\
\hline Vector-Borne Diseases & \\
\hline
\end{tabular}

- Health Economics

- Environmental Health

- Health Administration

- Occupational Health

- Health Systems

As for the Master of Public Health Sciences, even though all the programs have the common goal of training researchers and professors, programs vary from institution to institution. The following concentration areas were identified in the region:

- $\quad$ Epidemiology

- Clinical Epidemiology

- Biostatistics

- Environmental Health

- Health Economics

- Reproductive Health

- Health Systems

- Infectious Diseases

- Vector-Borne Diseases

- Nutrition

It is important to consider that environmental health is given little space within graduate level cur-
Table II

\section{Common areas among Masters in Public Health}

\begin{tabular}{ll} 
Country & Areas of Common Knowledge \\
Costa Rica, México, Colombia, & Epidemiology \\
Cuba, Nicaragua, Ecuador & Biostatistics \\
& Demography \\
& Health Systems \\
& Social Sciences \\
\hline México, Ecuador, Cuba, Nicaragua & Community Health \\
& Administration \\
\hline Costa Rica, México & Community Practicum \\
\hline México, Nicaragua, Colombia & Ecology \\
\hline
\end{tabular}

ricula; Mexico and Costa Rica are the only countries offering a program in the field, with a very small number of candidates.

In 2008, the Doctorate in Public Health program was created in Mexico at the National Institute of Public Health, this being the first doctorate program in the region with an applied approach. Emphasis on research and teaching stands out in countries like Mexico, with the Doctorate in Public Health Sciences, and Colombia (University of Antioquia), with the Doctorate in Public Health and Epidemiology.

\section{Competency-based Programs}

The Latin American Association of Schools of Public Health has stimulated the development of reforms of academic programs based on basic competencies to fulfill the EPHFs. ${ }^{7}$ Likewise, the Pan American Health Organization has contributed enormous efforts in support of strengthening policies, plans, and programs that favor the training of human resources in health based on such competencies. Four institutions with this approach in the region stand out: the Institute of Public Health and the University of Veracruz, in Mexico, the Central University of Ecuador and the Manizales Autonomous University, in Colombia. It should be noted that a high percentage of programs are currently involved in the competency-based redesign of their programs.

The Mexican National Institute of Public Health's experience in competency-based curricular design seeks to merge the realities between education and work, guide change processes in organizations and training programs, and seek a point of convergence between education, teaching, and work. 
There is still a need to complete the redesign process of all programs in the region in a competency-based format. In order to do so, more closely relationship between academia and health departments is needed to identify professional competencies, as well as competencies related to skills necessary for the job, such as, communication, leadership, team working, just to mention some cross-cutting competencies that public health personnel require and need to be included into the curricula.

In addition, the orientation of programs varies. Most of them still predominantly research oriented. The professional programs represent only $21 \%$ with a special focus to train professionals who assume leadership positions in health services, with a more practical approach toward problem-solving. There is a big need to increase the number of professional programs in the region. It was also found that these programs are perceived to be not as good as the research oriented programs. The schools authorities have mentioned that there is a lack of alternative options for graduation, in most programs thesis is the only option, even for the professional programs. Some schools are moving towards a more practical approach such as practicum experience, capstone course, case studies, but this has being very slow because they are perceived to be less demanding.

\section{Educational Models}

Educational models that emphasize a constructivist approach, adult education, and active learning that use collaborative learning, Problem-Based Learning (PBL), and case studies are starting to be developed in the region. Some examples of programs that have discussed and proposed an educational model are : the University of El Salvador (El Salvador); the University of Guadalajara, the National Institute of Public Health, the Tamaulipas Institute of Sciences and Higher Studies, the Autonomous University of Baja California, the Autonomous University of Juarez, and the University of Guanajuato (Mexico); the Central University of Venezuela; the Central University of Ecuador; and the Autonomous University of Manizales (Colombia). One model worth mentioning is that of the University of Veracruz, Mexico which, as a fundamental basis for its program design, very satisfactorily linked the Essential Public Health Functions with professional competencies. The University of Veracruz designed the Master of Public Health Curriculum that, under a modular system and with the concept of comprehensive learning, created specific learning-work environments. The curriculum consists of three stages: the first is disciplinary, the sec- ond deals with basic competencies, and the third deals with specific competencies.

\section{Delivery Methods}

The needs of the public health labor market have made it necessary for educational institutions in the region to seek viable alternatives to enable access to human resources training programs offered in the field. Existing academic formats offered include:

a) Full-time, classroom based: This format is used in bachelor's degree and undergraduate programs, and in most cases is also used for master's degree programs, as in Mexico at the National Institute of Public Health and in Colombia at the University of Antioquia. This continues to be the strongest format in the majority of cases due to the institutional requirement for full-time commitment and, in some institutions, as a condition of the economic scholarship offered to students.

b) Part-time, classroom based: This format is becoming increasingly popular as it is the most viable option given that students are immersed in the work field without the possibility of attending a full-time program. Under this format, the student generally attends on weekends, for blocks of two to three days, submitting academic assignments at certain times. Programs with this educational option that stand out include: the National Autonomous University of Nicaragua, Cuba's National Institute of Hygiene, Epidemiology and Microbiology, and Cuba's National School of Public Health, the latter having conducted human resources training in different countries across the region such as Bolivia, Mexico, Brazil, Ecuador, and Venezuela.

c) e-learning: This is an innovative format based on Information and Communication Technologies (ICTs). Its focus is on activities geared towards independent study and meaning-based learning. It also represents one of the best options for practicing health professionals, as long as the program possesses a solid pedagogical foundation and continually tracks students. Under this philosophy, Cuba's Pedro Kouri Institute and Mexico's National Institute of Public Health are worthy of special mention.

d) Blended-learning: Combines e-learning with classroom-based activities. Although few programs use this delivery method in the region, few experiences like the one at the National Institute of Public 
Health in Mexico and the Central University of Venezuela, have proven to be very successful and its use will increase rapidly in the near future.

In conclusion, the results of the research carried out show that of the 42 institutions surveyed, $40 \%$ use only a full-time face-to-face format; $22.2 \%$ have incorporated part-time face-to-face, usually on weekends; $15.5 \%$ of the institutions use different formats depending on the program; only $4.4 \%$ use an online format exclusively; one institution uses a mixed model combining face-toface with online; and $17.7 \%$ of the institutions did not specify their format in the information provided due to current changes in the delivery formats.

\section{School or Program Accreditation}

Certification is the process by which an independent and recognized institution provides a product, process, or service (or several of the aforementioned, in the case of an institution) and conforms to a nationally or internationally accepted standard of quality. Promoting the processes necessary to achieve certification in an organization is a fundamental step in effectively achieving the improvements needed. ${ }^{8}$

There is a lack of accreditation of public health programs throughout the region studied. Most of the programs belong to a university certified by their local ministries of education and they might also belong to a public health organization such as ALAESP (Association of Public Health Schools in Latin America), AMESP (Association of Public Health Schools in Mexico), and ENSAP (National Institutes and Provincial Centers in Cuba). Such associations bring together activities in academic institutions with services through scientific/ technical coordinative and cooperative relationships, but they are not necessarily accreditation bodies.

In Mexico, the National Council on Science and Technology (CONACyT) is an accreditation body for graduate programs and seven institutions offering public health programs are accredited and provide scholarships; CONICIT in Costa Rica is a similar example. In addition, the Council on Education for Public Health (CEPH), an independent agency recognized by the United States Department of Education, accredits public health programs and schools. Mexico's National Institute of Public Health is the first non-US institution to receive this accreditation. It is important to note that although the U.S. is not part of the region studied, its work and support in the field of public health and its close collaboration with some institutions in Latin America and the Caribbean is recognized. Regional public health associations must advance the agenda of accreditation in public health to ensure quality training.

\section{Faculty}

In order to guarantee the quality of programs, major efforts in the region have been made to train professors who participate in public health programs. In general terms, all of the graduate programs require a master's degree in order to conduct academic sessions, and Cuba is one of the few countries where almost all of its faculty members possess a doctorate degree. It is important to note that a significant percentage of faculty has being trained in the United States of America, while Nicaragua has a collaborative agreement with Sweden for faculty training, Cuba has trained faculty for certain countries and, historically, Mexico has also trained faculty for all Latin American countries.

Recruitment of Master of Public Health graduates for teaching purposes is notable in the region, this being a viable work option for those who graduate from these programs. The number of members who make up a faculty varies dramatically across the region; for example, in countries such as Guatemala, there are approximately 10 combined full-time and part-time professors to support the programs, Colombia has more than 25, and in Mexico there are more than 200 full-time professors at the National Institute of Public Health.

One feature of the region is that most of its faculty hold research oriented academic-degrees, and this situation does not favour the more practical and professional programs. In addition, there is a lack of teaching personnel trained in teaching techniques, so the classes tend to be traditional, favoring research over more practice-related approaches. Some institutions, such as The University of Antioquia in Colombia and the National Institute of Public Health in Mexico, have addressed these problems and to improve teaching performance they are offering, as well as requiring teaching courses for faculty.

A minimum of a master's degree for teachers in graduate programs is a consistent requirement in the majority of institutions. In recent years, however, institutions are also requiring command of a second language, academic honors, publications, research projects, and a pedagogical proposal in order to participate as professors in public health; Colombia is a good example of this.

Faculty promotion in the region, is mostly based on research work. There is a big challenge that the schools are facing to favour teaching as much as research for compensations and promotion. 


\section{Admission Requirements}

There is a variety of admissions processes among the different institutions in the region, ranging from measurable criteria to in-service vocational aspects, interest in public health, work experience, etc. Among the measurable criteria, common requirements such as a bachelor's degree, basic or intermediate levels of English, and knowledge of computer software can be identified. Nevertheless, the lack of homogeneity in criteria is notable, as some institutions define an admissions profile while others indicate only the type of process that must be carried out or the documentation that must be presented.

It must be stressed that within this great variety, it can be observed that some institutions favor a series of exams aimed at exploring general knowledge or knowledge specific to the field, while others give greater weight to the applicant's work experience. In almost $90 \%$ of the countries studied, the entrance exam is defined by the institution itself- - that is, no national graduate admissions evaluation instrument exists to determine the general skills necessary for an applicant to achieve optimum academic performance; in the case of Mexico, however, a general graduate admissions exam exists that can be added to the application for admission to a higher education institution. This exam is created by the National Center for Higher Education Evaluation (Ceneval), a civil non-profit association whose main activity is the design and administration of instruments to assess knowledge, skills, and competencies, as well as the analysis and distribution of test results.

It is important to note that the professional profile sought as part of the graduate admissions requirements tends to break the boundaries of the exclusively medical field. That is, a high number of institutions make themselves available to professionals in the field of social, administrative, and environmental sciences, among others. This accessibility is an indicator that public health is a vast field for action and for the generation of knowledge; it allows the participation of many disciplines that revolve around a common objective -improvement of the population's health. ${ }^{9}$

\section{Student Tutoring Program}

One aspect that is difficult to evaluate is whether an institution has a well established tutoring system that provides the student with a guide for the duration of the graduate study and enables the student to achieve the objectives of the program as well as his or her expectations. This is because the information available does not indicate the characteristics of this system, much less its results. The tutoring program, understood as an accompaniment to the student from his or her enrollment until graduation, is more frequent at the bachelor's or undergraduate level than the graduate level. The University of Costa Rica should be noted as one of the few institutions with a strong student tutoring program, having created the role of Master's Professor-Advisor, who is responsible for guiding and accompanying students from the time they enroll to the time they complete their academic work. Likewise, the tutoring experience at the University of Antioquia stands out with a program of this nature at the doctorate level in which the student, during the three-year stay, relies on the support and guidance of a professor who may also become the thesis advisor.

At the graduate level, various institutions mention having an Institutional Tutoring Program that focuses solely on advising dedicated to the final thesis work. In this regard, Rafael Landívar University and the Central University of Ecuador are worthy of special mention, as the latter clearly establishes that 50 hours be dedicated to this task per month, per student, on a schedule agreed upon with the tutor.

\section{Scholarship Program}

One of the main regional limitations of graduate education in all of the full time programs is lack of financial support to complete the corresponding studies. This is the main reason that educational institutions have had to seek new educational formats to meet the demand for the training of public health professionals.

There are few institutions that have a solid scholarship system; one that does and is worthy of special mention is the scholarship system at the University of Guadalajara in Mexico, whose main objective is the promotion and diffusion of scholarship announcements. The National Institute of Public Health, also in Mexico, has access to CONACyT scholarships for graduate students, as do the National Autonomous University of Mexico, the University of Veracruz, and four other state universities. At the University of El Salvador, two scholarship programs exist: one with the Socioeconomic Studies Unit and another with the Scholarship Council. The National Autonomous University of Nicaragua has a program with different types of scholarships: an "external" scholarship consisting of monthly remuneration; an "internal" scholarship consisting of lodging, food, support for study materials, and other subsidies; one based on academic excellence, serving as well as an additional stimulus for good performance; a service scholarship; and a tuition aid grant, which offers an exemption from payment of tuition in special cases. 
The lack of graduate level scholarship programs was also one of the reasons for offering part-time weekend options in order to give students the opportunity to continue with work activities and earn the corresponding salary. In addition, in some countries, such as Colombia, there are opportunities for students to participate in research projects or other undergraduate professorships in exchange for economic remuneration.

\section{Fieldwork Experience}

Despite the fact that fieldwork is of fundamental importance to training public health professionals, few institutions clearly specify whether they include this experience within their curriculum and what type of results they obtain. It should be clarified that this does not mean that they do not include this experience, but rather that institutions do not specify them when providing information on their graduate programs or they do not do it in a systematic manner.

In Mexico, at the National Institute of Public Health, the Master of Public Health program community practicum is a required course in all concentration areas. Students carry out a population health evaluation, complete a process of prioritizing health problems, and implement a community health intervention, thereby applying the theoretical and methodological knowledge gained in the classroom.

At the Autonomous University of Nuevo León, community studies are carried out after completion of coursework for the Master of Public Health, and at the University of Veracruz population health evaluations are conducted with specific interventions for a priority problem. The National University of Colombia has a range of opportunities for fieldwork experience, beginning at the undergraduate level, but with special emphasis at the graduate level. In Mexico, the experience of the Autonomous Metropolitan University is worth noting, as it has a model based on community work for its Master of Community Health. In general terms, there is an increasing tendency to include community practice as an essential part of public health programs.

\section{Alumni Tracking Program}

An important aspect, yet frequently forgotten by educational institutions, is tracking alumni to maintain a permanent link for reinforcement and updating. The scarcity of information on alumni in public health human resources training institutions in the region can be noted, as the majority of them do not report having an alumni tracking program or system, much less alumni academic activities, particularly at the graduate level.
The University of El Salvador, the Central University of Ecuador, the University of San Luis Potosí, and the University of Guanajuato in Mexico are among the few who do track alumni. There are some recently created programs, as in the case of the University of Antioquia of Colombia, that offer employment opportunities in teaching and research as well as doctorate training.

Two notable experiences include the National Institute of Public Health in Mexico and the Autonomous University of Manizales in Colombia. The latter has an Alumni Association whose objectives are to boost scheduled activities that allow alumni and their programs to be strengthened, to promote alumni professional development, and to create links among members, the university, and national and international entities. At the National Institute of Public Health in Mexico, there is a formal Alumni Academic Program that includes e-learning courses, an electronic bulletin, a yearly social and academic event, and a particular space in the institution's webpage for alumni services.

From the institutions that track students although not sistematically mentioned that their graduates are working mainly in local health systems, health centers, institutions of higher education, and civil organizations.

\section{Continuing Education}

Continuing education, which involves training and the updating of competencies, is fundamental in an institution of higher education aimed at educating public health professionals. It is, therefore, imperative that institutions have formal and well-structured continuing education programs, in close collaboration with the Health System, in order to train in service personnel in basic public health competencies, as well as cross-cutting and emerging competencies.

There are no experiences in the region where continuing education programs are established taking into account national competencies for performing public health functions, needs-assessment and training programs that address those needs. Most of the academic institutions develop their programs according to their agenda, with little link to the national health systems and programs.

Agood example of a strong link between academia and health system is Cuba, with well established and effective continuing education programs, Pedro Kouri Institute of Tropical Medicine, offers certificate and non-certificate courses in Health Management, Health Promotion, and Health Economics, and Cuba's National Institute of Hygiene, Epidemiology and Microbiology with training courses in Biostatistics, School Health Promotion, and Environmental Health. 
In Mexico, continuing education programs have become increasingly important to support the National Health Plan. Academic institutions as well as the educational departments of the health systems offer a vast array of courses and certifications. The National Institute of Public Health offers in the summer more than 50 courses in different areas of public health. Throughout the year, the institute develops costume-made courses that are delivered in the different states and on-line. Other Mexican institutions that have continuing education programs are: the Autonomous University of Juarez with a certificate course in Occupational Safety and Health Administration; the National Autonomous University of Mexico with a program composed of a variety of courses, including certificate courses in the field, and the Autonomous University of the State of Mexico, with training in Health Services Management, Health Economics, and Occupational Health and Medicine. Other examples are the University of Costa Rica, the Central University of Ecuador with certificate courses that tackle various operational aspects of public health, and the Autonomous University of Manizales with courses aimed at sexual and reproductive health, population health, and public health policy development.

Further, continuing education in the region has been fundamental to the processes of health system reform. In Panama at the Gorgas Memorial Institute of Health Studies, the primary objective was to equip decision makers to manage and control HIV/AIDS and other infections in the region.

The Costa Rican Institute for Research and Teaching in Nutrition and Health (INCIENSA) has a program for diabetes education for primary health care. In Mexico, the Leadership Unit at the National Institute of Public Health, is an initiative to train and update officials at the strategic, tactical, and operational levels of the National Health System

Graduate education in public health is a fundamental process for the development of health. Well-informed specialists will be those who lead efforts in order to prevent, address, and anticipate problems that affect the public's health. ${ }^{10}$ For this reason, human resources and their education and training are critical and capable of making a difference in the improvement of the region's population health.

This education must concentrate on degree progra$\mathrm{ms}$ as well as long-term continuing education initiatives with the purpose of graduates actively participating in changing necessary and essential health systems. It is these graduates who have the social responsibility for the proper functioning of public health services. ${ }^{11}$ The demand for accessible, quality, and professionally recognized training comes not only from professionals, but also from the system itself and a multitude of agents and institutions play a role in responding to this demand, whose joint action offers a unique opportunity to improve public health as a discipline, a profession, and a health tool for the population.

\section{Public Health Personnel, Human Resources, and Employment Conditions}

Institutions that train public health personnel, their curricula, and their general policies must be taken into account in the field of professional practice and in the daily work responsibilities and activities of health personnel. There are few studies that have advanced the analysis of the relationship between the world of educational institutions and the world of work. The information presented in this section focuses on the general quantifying of human resources for health, followed by a discussion of particular employment conditions for personnel that have been trained in public health.

\section{Human Resources by Country}

The results of our study indicate that information available is scarce and atomized. In the great majority of countries there is no precise information on the total number of workers employed in the health sector (only for Colombia, Cuba, and Mexico) or the total number of public health workers in the area of public health. Another difficulty is that there is no individual data for occupational categories; only in Belize, Guatemala, Honduras, and Panama was there a group of health personnel characterized as Public Health Workers and Environmentalists. For the rest of the countries it was only possible to establish the number of medical, nursing, and dental personnel.

With respect to the rate of physicians per 10000 habitants, Cuba has 63.4; Costa Rica 20.0, and Venezuela 19.4. The lowest are Ecuador with 1.4, Haiti with 2.5, and the Dominican Republic with 1.8. With regard to nurses, Cuba, Dominica and Grenada are worthy of special mention.

In addition, Cuba, Colombia, and Costa Rica have the greatest proportion of dentists, while Honduras, Haiti, and Ecuador have the least. With respect to nursing assistants -many of whom perform public health tasks- information could only be gathered for six countries. 


\section{Conditions in the Labor Market}

Regarding public health personnel's situation in the labor market, it can be stated that there are problems common to the rest of the workforce employed in the sector. Over the last decade, Observatories of Human Resources in Health, led by the PAHO (among other dissemination efforts promoted by the institution) have shown with exceptional depth and detail a general tendency toward change in work conditions, expressed in the loss of contractual benefits, increased flexibility in hiring methods, coexistence of various work regimes for similar occupational categories, and new payment mechanisms where productivity has at times been a determining factor for defining income, among other adverse conditions for health personnel. ${ }^{12,13}$

In a text on the challenges of human resources management (PAHO, 2006), some of the working conditions of health human resources within Latin America is summarized:

Outsourcing and subcontracting activities (e.g. cleaning, food, and security services) belong within this contextual framework and analysis. In their earliest appearance, these activities were focused in the area of general services, but currently they offer other professional services through the hiring of medical cooperatives and of nursing organizations for home care or rehabilitation, among others.

In one of the recommendations for Central America regarding the income of health personnel made by the PAHO's Plan for the Decade of Development of Human Resources, the need for improvement is recognized as a fundamental factor to advance the workforce's performance, motivation, and commitment to its mission. Budgetary limitations in various countries are acknowledged and the benefit of involving workers and their organizations in "the formulation of policies and planning so that it is easier to arrive at conciliatory formulas" ${ }^{15}$ was proposed.

Another problem about which little is known relates to labor wastage (unemployed + those who dedicate themselves to issues unrelated to their professional training) of public health personnel. In the case of Mexico, this has been calculated for five occupational categories in the health field. One of these categories includes nursing technicians who, because of the activities they perform, can be considered as public health actors. According to preliminary results of a study, in 2004, $33.1 \%$ of these nurses was unemployed and another $27.4 \%$ was employed outside of the field; that is, a $60.5 \%$ labor wastage. ${ }^{16}$

In addition, an initial qualitative survey indicates that the positioning of public health personnel in the workforce in Mexico, Central America, and the Caribbean has not been successful. For example, in Costa Rica (according to the Costa Rican Public Health Association, comprised of 265 people), personnel trained in public health work mainly in the public sector in rural areas, those that are hired by the Costa Rican Social Security Administration have work conditions and incomes similar to clinical physicians, while those employed by the Ministry of Health have incomes that are 50\% lower.*

In Nicaragua, there was a temporary increase in national public health personnel (initially trained in Cuba) in the 1980s during the first Sandinista government, but twenty years later, a new concern with training public health personnel was noted, with the majority of these personnel being professionally engaged in urban areas. However, with the significant presence of European organizations, work and research in rural areas has been stimulated, causing a good deal of mobility among public health professionals. Often these personnel work for UNICEF, as this organization has an important presence in Nicaragua. Working for this organization or for European NGOs is one of the greatest aspirations, as employees obtain high incomes and also have opportunities to travel to European countries. The average monthly salary in the public sector is USD 350, in addition to vacation, savings account, pension, and food vouchers. Those who work for a European organization in a rural community can have monthly incomes reaching up to USD 2,000. ${ }^{\ddagger}$

In the case of Panama, personnel trained in public health are mainly employed by the Ministry of Health and the Social Security Administration and, to a lesser extent, by the central hospital, the board, and by civil society organizations. The majority are concentrated in the capital city, although a portion of these personnel is distributed across the 14 health regions into which the country is divided, where some act as regional directors. $\S$

In Guatemala, the main employer of personnel trained in public health is the Ministry of Health, whose staff is considerably concentrated in the country's capital city. Including epidemiologists, around 80\% occupy administrative positions in different levels of the Ministry and in the departments into which Guatemala is divided. The majority of these personnel have incomes of less than USD 2,000. During the last 10 years they have

\footnotetext{
* Telephone interview with a representative of the Costa Rican Public Health Association, June 16, 2008.

₹ Telephone interview with a representative of the Nicaraguan Public Health Association, June 19, 2008.

$\S$ Telephone interview with an official of Panama's Ministry of Health, June 23, 2008.
} 
not held long-term jobs, which tend to disappear, and are considered contract employees -that is, they do not have job stability or employment benefits. NGOs that provide health services, contracted by the Ministry of Health, have at least one epidemiologist on their staff who may earn $20 \%$ less income than staff employed directly by the Ministry. In contrast, international NGO employees earn higher incomes than public personnel. Less than one percent of all personnel in the Guatemalan Social Security Institute have training in public health, are categorized as medical professionals, and earn incomes 50\% higher than staff employed by the Ministry of Health.*

In the case of Honduras, there are an estimated 300 public health specialists. The majority of personnel trained in this area is employed by the Ministry of Health and generally occupy management positions, at a minimum as directors of health centers; few have contact with patients. The majority is concentrated in the main metropolitan areas and their average monthly income is USD 1,900. The country's health service providers are divided into 20 departments and not all of those departments have public health personnel. The staff that works at the Ministry has an appointment that guarantees job stability and has access to conventional benefits such as year-end bonuses, vacations, and pensions at 60 years of age. A minority also works at the Honduran Social Security Institute. Other emerging employers are NGOs, who in the last ten years have shown a tendency to hire public health personnel. Those who work for such organizations do so on a contract basis without any kind of employment benefits. ${ }^{\ddagger}$

In Ecuador, 260 public health specialists were trained from 1981 to 2006, and 58\% of those are women. ${ }^{17}$ It was not possible to obtain information regarding the labor market at the Central University or at the Ministry of Health. Both sources expressed that exact employment information on public health specialists is not known. $\S$

Another emerging phenomenon, with diverse manifestations, is the movement of health human resources in various directions within the American continent and, to a lesser extent, to Europe..$^{18} \mathrm{Cuba}$ sends out the most physicians and nurses, mainly to Belize, Venezuela and, to a lesser extent, Nicaragua."

\footnotetext{
* Telephone interview with a director of Guatemala's Department of Health Sciences, June 24, 2008.

₹ Telephone interview with a director of the National University of Honduras Department of Medical Sciences, June 24, 2008.

$\S$ Telephone interviews with directors of both Ecuadorian institutions, June 26 and 17, 2008.

* Personal interview with Cuban teacher/researcher, June 6, 2008, Guerrero, Mexico.
}

In Panama, movements of personnel trained in public health were not recorded. In the case of Guatemala, an informant stated that Guatemalan personnel do not leave the country to work abroad, and that they receive people from Cuba, Chile, and Colombia who work in management positions in the national health system. ${ }^{*}$

Who makes up the public health workforce?

First, the major gaps in information existing in practically all of the countries considered should be recognized. This is something that has already been accepted in the studies used to construct the Observatories of Human Resources, and specific recommendations to create and / or improve information systems on the health workforce have been made. ${ }^{19}$ In addition, there are difficulties in accessing the little information that exists.

It should also be considered that, in statistical data as well as qualitative analysis, different criteria and classifications are used to determine who makes up the public health workforce. Within this framework, it is helpful to initially consider a general classification into two groups:

a) People who studied a specialty (bachelor's degree and/or graduate degree) in any aspect of public health.

b) Occupational categories that perform work related to public health in their daily practice (e.g. primary care medical personnel, nursing technicians and assistants, health promoters, primary care technicians, laboratory technicians, and dental technicians).

With respect to the first group, it is possible to formulate the following hypothesis based on empirical data: the majority of personnel trained in educational institutions as public health specialists does not work in primary care, is concentrated in urban areas, is not in contact with the population, and is partially dedicated to coordinating programs related to their specialization at the regional, municipal, or state level. In the labor market this category is confused with and/or refers to a specialist with a lesser status, in terms of income ranking, as compared to clinical specialists who traditionally have enjoyed social prestige and higher economic status (for example, surgeons, gynecologists, etc.); their income can be less than clinical specialists while they are also subject to flexible types of labor contracts.

${ }^{\infty}$ Telephone interview with a director of Guatemala's Department of Health Sciences, June 24, 2008. 
In regard to the second group, their work is not recognized as an important contribution to public health actions. The majority of the occupational categories that fall into this category belong to the lowest levels, both in the hierarchy and with regard to income. Some of these workers are not considered part of the public health workforce.

There are issues common to both groups that are fundamental in considering the design of policies regarding training and employment. The "public health workforce" cannot be developed in a vacuum. All plans to strengthen public health human resources depend on the development and continuous improvement of all health human resources, as well as the infrastructure that sustains them and the system in which they operate. Allocation and distribution plans, retention and recruiting strategies, promotion work, and policy formulation are all part of the development of the health workforce. ${ }^{20}$

Although efforts by PAHO, such as the Human Resources Development Programs and the Observatories, have been significant, there are still many factors to be investigated and analyzed regarding the conditions of public health personnel in the work world.

\section{Discussion}

Some programs are currently involved in the process of redesigning its curricula. In the next years, there is a great pressure to ensure that all public health programs should be competency-based to deliver appropriate, meaningful, and pertinent education.

There is a need to closer collaboration between academia and health departments to define professional, emergent and cross-cutting competencies for public health personnel.

Few programs in the region emphasize prevention, health promotion, and primary healthcare.

In the future, the region will diversify the delivery formats to be more flexible, and incorporate strategies such as executive, weekend, and online programs.

For personnel carrying out public health tasks, it is important to design continuing education strategies to update knowledge in light of new competencies with innovative delivery formats to guarantee accessibility.

All continuing education offerings should be adjusted to the specific needs of health systems, particularly to the new epidemiological profiles common among countries.

To innovate instruction, faculty should be required to be trained in teaching methodologies such as case studies and problem based learning.
Faculty compensations and promotion is largely based on research. Teaching has to be professionalized and recognized for promotion.

The majority of institutions in the region that train public health personnel lack a program to track alumni. Institutions should implement programs that provide information on whether trained personnel are employed, where they are employed, employment conditions, social mobility, and above all, if they are applying knowledge received and if they need updating.

Regional public health associations must advance the agenda of accreditation to ensure quality training.

In the labor market throughout the various countries in the region, public health personnel work in a wide range of activities not strictly related to their academic training.

Having a graduate degree in public health does not imply that graduates improve their employment conditions in economic terms, status, or hierarchical level.

In countries within the region there is no coordination between institutions that train public health personnel and employer institutions. Efforts have been undertaken, but their achievements have been limited.

In terms of the current regional context, it is beneficial to develop public health human resources that respond to national and regional needs.

Information available on the number of people trained in public health and their position in the labor market is extremely limited throughout the entire region. Therefore, common national and regional strategies urgently need to be defined for the construction of a better information system with consistent indicators.

\section{Acknowledgments}

We appreciate the cooperation of the following institutions in the integration of this report: Carlos A. Agudelo C., Universidad Nacional de Colombia; Pastor Castell Florit -Serrate, Nereida Rojo Pérez, Ileana Morales Suárez, Escuela Nacional de Salud Pública de Cuba; Miguel Orozco Valladares y Manuel Martínez Moreira, Universidad Autónoma de Nicaragua; Patricia Aleen Flores, Instituto Costarricense de Investigación y Enseñanza en Nutrición y Salud; Jorge Motta, Instituto Conmemorativo Gorgas de Estudios de la Salud, Panamá; Enrique Hernandez Guerson, Instituto de Salud Pública de la Universidad Veracruzana; Rodolfo Méndez Vargas, Claudia Iglesias Padrón, Irma Sánchez Salazar, Jesús Vértiz Ramírez. Instituto Nacional de Salud Pública. 


\section{References}

I. Organización Panamericana de la Salud / Organización Mundial de la Salud. La Salud Pública de las Américas: Funciones Esenciales de la Salud Pública.Washington; 1997.

2. Silvestre Oramas M. Diagnóstico pedagógico, curriculo escolar y calidad de la educación. Perspectivas (UNESCO) 2003; 33 (I): I-I2.

3. Frenk J. Dimensions of health system reform. México. UNAM; 1994. 4. Organización Panamericana de la Salud. Asociación Latinoamericana de Escuelas de Salud Pública. [documento en internet]. 2008 [citado 2008 junio 23]; Disponible en: http://www.alaesp.sld.cu/

5. Pérez Cárdenas M, Martínez Cruz E, Díaz LLanes G. Estado actual en la formación académica de postgrado en salud pública en Hispanoamérica. Revista Habanera de Ciencias Médicas 2007; 6(4): 6-8.

6. Universidad de Antioquia. Tendencias y teorías en salud pública. Medellín: Facultad de Salud Pública; 2006.

7. Louro Bernal I. Funciones esenciales de la Salud Pública en programas de maestrías de la Escuela Nacional de Salud Pública.Año 200I. Revista Cubana Salud Pública 2002;28(I):46-53.

8. Magaña L. La certificación, garantía de excelencia en el contexto internacional. Salud Publica Mex 2006; 48 (4): 29I-292.

9. López Cervantes M. La construcción de una nueva salud pública. Una tarea multidisciplinaria. Salud Publica Mex 1997; 39 (3): I77-178.

10. Borrel RM. La formación de posgrados en salud pública. Organización Panamericana de la Salud 2004; 59: 9.
II. Medrano Albero Ma José.Aprender / Enseñar salud pública. Educ. méd. [periódico en la Internet]. 2003 Sep [citado 2008 Jul 23] ; 6(3): 18-19. Disponible en: http://scielo.isciii.es/scielo.php?script=sci_ arttext\&pid=S| $575-18|32003000300010 \&| n g=e s \& n r m=i s o$.

12. Brito P. Desafíos y problemas de la gestión de recursos humanos de salud en las reformas sectoriales. OPS. Washington DC.

13.Arroyo J. Situación y desafíos en el campo de los recursos humanos en salud en el Área Andina, en los albores de los 2000. Anales de la Facultad de Medicina, Universidad Nacional Mayor de San Marcos, 2002; 63 (3): 212-222

14. Desafíos de la gestión de los recursos humanos en salud, 2005-2015. OPS. 2006.

15. Plan decenal RRHH Centroamérica - Actividades de cooperación técnica a nivel subregional. OPS. Honduras, 2006.

16. Nigenda G, Ruiz JA, et al. Boletín electrónico. Recursos humanos para la salud. Formación, empleo y regulación 2008; (7) [citado 2008 junio 16]. Disponible en: www.funsalud.org.mx

17. Merino C. El Talento Humano en los Umbrales del Nuevo Milenio. 2da ed. Quito: OPS; 2008.

18. Organización Panamericana de la Salud. Plan decenal RRHH

Centroamérica - Actividades de cooperación técnica a nivel subregional. Honduras: OMS; 2006.

19. Los recursos humanos de salud - retos fundamentales para la región de las Américas: mesas redondas. $58^{\mathrm{a}}$ sesión del Comité Regional. Washington, D.C., EUA: 2006.

20. Organización Panamericana de la Salud. Estrategias para desarrollar las competencias para la salud pública en la fuerza de trabajo. Washington DC, EUC: 2006. 